\title{
Phenotype and Surgical Treatment in a Case of Proteus Syndrome With Craniofacial and Oral Findings
}

\author{
REINHARD E. FRIEDRICH \\ Department of Oral and Craniomaxillofacial Surgery, \\ Eppendorf University Hospital, University of Hamburg, Hamburg, Germany
}

\begin{abstract}
Background/Aim: Proteus syndrome is a sporadic disease that is particularly noticeable due to the disproportional growth of body segments. The disease is a genetic mosaic. The mutations can arise from any of the germ layers, an explanation of the very variable phenotype. The aim of this report is to communicate the diagnosis and management of an unusual case of Proteus Syndrome with special attention to oral and craniofacial findings. Case Report: A 15-year-old patient was referred for surgical treatment of pronounced skull malformations and correction of oral mucosal hyperplasia. Treatment caused significant improvement in facial appearance and oral soft tissue conditions. Conclusion: Surgical measures adapted to the local findings and symptoms can often relieve severe disfigurement of the patient.
\end{abstract}

Proteus syndrome is a very rare disease which causes a plethora of differentiation disorders and predisposes to certain neoplasms due to early somatic mutations during ontogenesis (1-3). A standardization of findings and symptoms characterizing the entity has been difficult to achieve (4-10) (Tables I and II). The eponymous designation of the disease refers to the diversity of the phenotype (4). In Greek mythology, the sea god Proteus appears on earth and transforms himself into numerous shapes, predominantly to escape captivity. Referring to his capacity of metamorphosis, the medical term 'Proteus' syndrome gives the appealing nominal metaphor for the

This article is freely accessible online.

Correspondence to: Reinhard E. Friedrich, MD, DMD, Ph.D., FEBOMFS, Department of Oral and Craniomaxillofacial Surgery, Eppendorf University Hospital, University of Hamburg, Martinist. 52, D-20246 Hamburg, Germany. Tel: +49 40741053259, e-mail: rfriedrich@uke.de

Key Words: Proteus syndrome, osteotomy, gingival hyperplasia, overgrowth syndrome, swallowing dysfunction, spine deformity, cerebriform connective tissue nevus. characteristic and diverse deformations experienced by affected individuals.

The excessive growth is particularly noticeable when the skeleton is affected. Differences in length and circumference of extremities are just as characteristic of the syndrome as excessive growth of one or more skull bones. The skull is frequently affected by asymmetrical local growth (11). The osseous overgrowth can cause considerable aesthetic and functional impairments (12-15). The report describes diagnostics and treatment of a patient with Proteus syndrome with special consideration of the craniofacial and oral regions.

\section{Case Report}

Medical history and physical findings. The 15-year-old female patient was referred to the outpatient clinic of the Department of Oral and Craniomaxillofacial Surgery for treatment of known Proteus syndrome with pronounced craniofacial deformities. It was a sporadic case of disproportionate growth disorders. On admission, the patient was slim (80 kg body weight) concerning her unusually tall height $(196 \mathrm{~cm})$. The patient's medical history disclosed an insulin-dependent type I diabetes mellitus, which had been diagnosed several months before, and hypothyreosis following Hashimoto thyroiditis, known for several years.

There was a difference in size between the halves of the body in favor of the left side. The patient had an inclined pelvis resulting of asymmetrical growth in the lower extremities. Orthopedic interventions had already been carried out to compensate the leg length difference and reduce the asymmetry of lower extremities' bones, including wedge excision of growth plates.

The patient's skull was unusually large in general, presented as dolichocephaly and was asymmetrically shaped due to localized osseous growth excess. There was a distinct skeletal plus in favor of the calvarial right side. However, the osseous mass of the forehead was almost centrally located and considerably protruding. In contrast, the glabella appeared flat and the transition to the bridge of the nose was broad and somewhat trough-shaped. The hypoplasia of nasal 

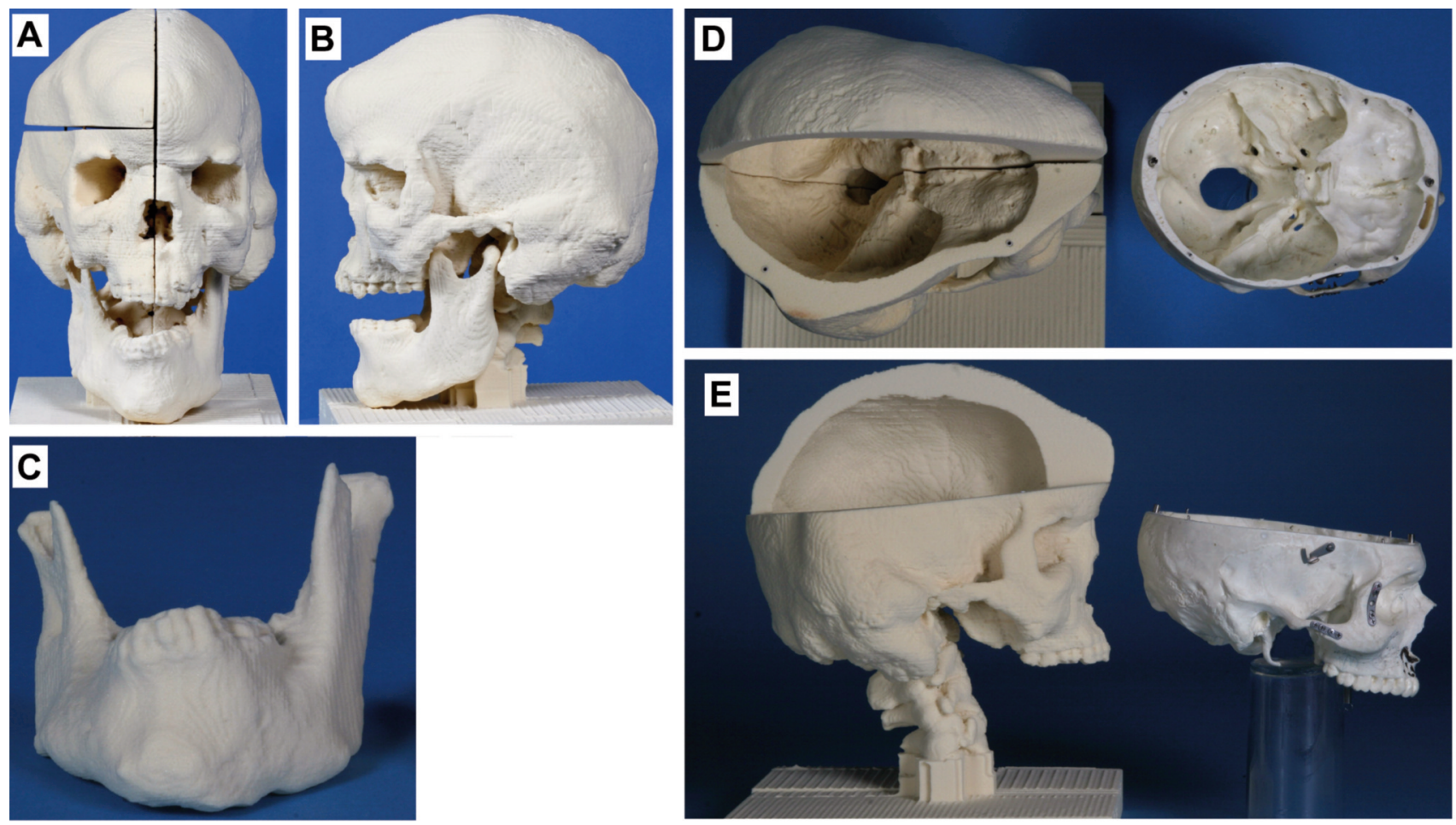

Figure 1. Three-dimensional plastic model of the patient's skull derived from computed tomograms. An artificial model of the skull is shown in Figures $1 D$ and $1 E$ for size comparison. (A) Anterior view with asymmetrically developed calvaria, prominent frontal (bossing) hyperostosis. The supraorbital margins are enlarged. (B) The frontal hyperostosis essentially determines the expression of the profile. Besides frontal hyperostosis, the lateral view of the skull shows excessive growth of the parietal, temporal, and occipital bone. In contrast, the nasomaxillary complex appears underdeveloped around the aperture. The mandible is shown in Figures A and B to illustrate the proportions and in a non-articulating position. (C) Anterior view of the mandible. The asymmetry of the rami is obvious. The mandibular corpus is greatly enlarged on both sides, especially in the cranio-caudal direction. (D) Top view of the skull base after lifting the right side of the skullcap. The calvaria is unevenly thickened. The dolichocephalus is particularly visible in this view. The foramen occipitale magnum is narrowed, which is noticeable in comparison to the exposed skull base of the skull model (right side). (E) The figure shows the thickened calvaria and the enlarged cervical vertebrae with pronounced lordosis. Artificial skull model positioned to the right of the patient model for size comparison.

bones and medial orbital processes of the maxilla, which was only apparent, was caused by the bulging tumor mass of the forehead. However, the maxilla around the apertura piriformis appeared underdeveloped in sagittal projection. The patient had downslanting palpebral fissures and minor ptosis. The orbital cavity was of normal size. Figure 1 shows different aspects of the patient's skull on her threedimensional skull model.

Both the upper and the lower jaw were developed asymmetrically. Both jaws were considerably enlarged in transverse and cranio-caudal dimension. The vertical enlargement of the viscerocranium contributed significantly to the aspect of the long face. The difference in the vertical dimension of the rami is obvious. The distance between the mandibular canal and the apices of the dental roots was considerable. The asymmetry of the lower jaw also affected the size and shape of the mandibular foramina. There was a discrepency of mandibular canal diameter in favor of the left side.
The mouth opening was unrestricted at the time of first investigation and this finding did not change during the follow-up of craniomaxillofacial surgical treatment. Mouth was open at rest. Oral inspection revealed generalized hyperplastic oral mucosa and prominent alveolar processes. The patient reported the overgrowth of the oral mucous membranes was first noticed when she was about 10 years old and this finding had increased slowly since then. The tongue was developed symmetrically being of normal size and function. The palate was high arched. The epithelium was of physiological transparency and not inflammatory; leukoplakia was not observed. The oral soft tissue hyperplasia was apparently caused by the mucosal connective tissue. The plus in connective soft tissue caused partial coverage of several tooth crowns by the gingiva and impaired tooth cleaning. The size and shape of teeth was in the normal range. No enamel dysplasia was observed. The dentition showed crowding of anterior and some premolar teeth and compromised occlusion. 

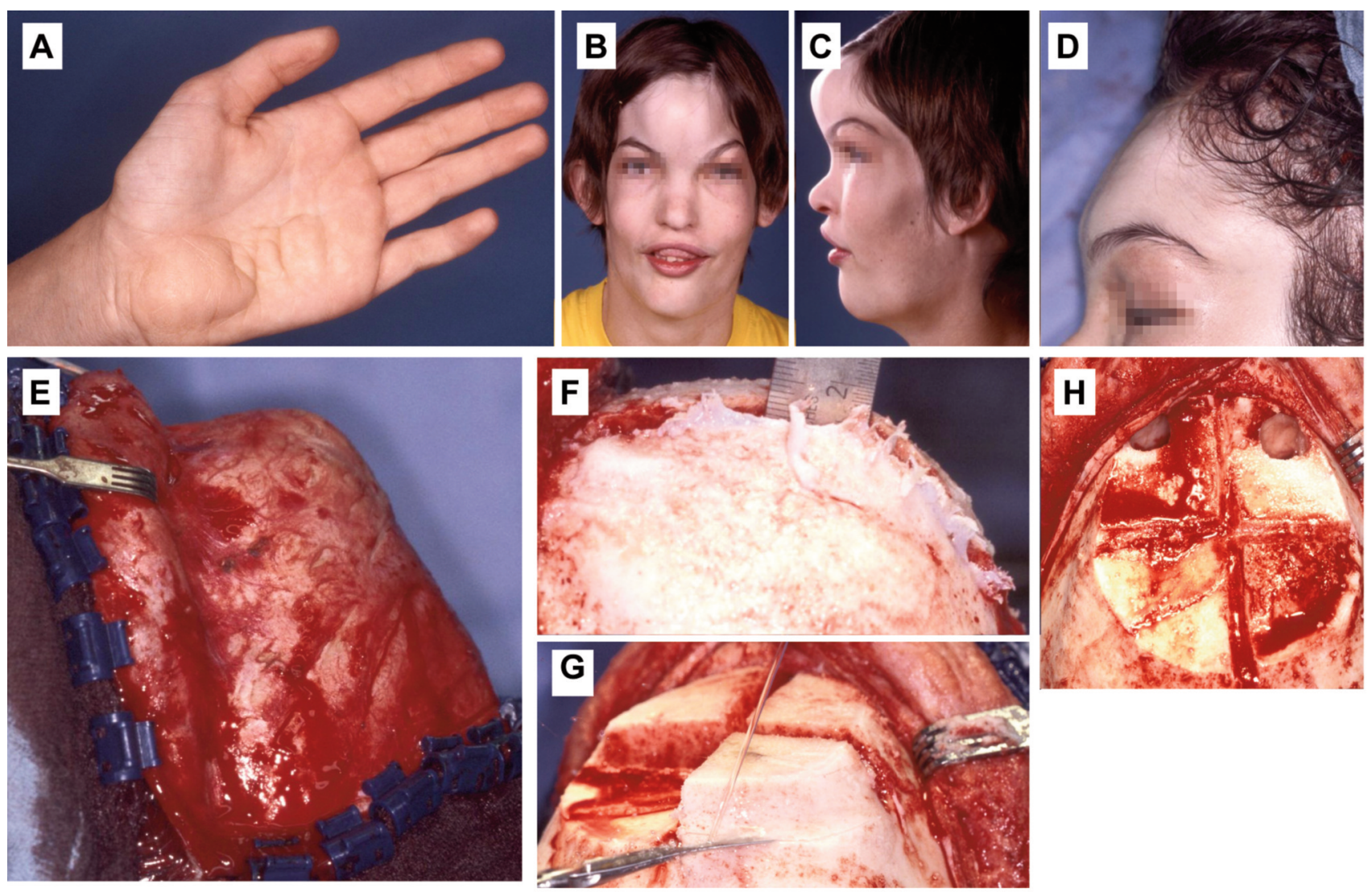

Figure 2. Clinical findings in the patient with Proteus syndrome. (A) Cerebriform cutaneous tissue nevus of left palmar region. Photographs (B) en face and $(C)$ profile of the patient showing a large face with prominent frontal bone, slightly downslanting eye lids, mild ptosis, and mouth open at rest with prominent upper jaw mucosa. (D) The frontal bone appears of normal shape after debulking procedure. (E) Aspect of the frontal bone prior to ablative surgery. $(F)$ The figure shows the diameter of the bone to be ablated. (G) Photograph of segmental frontal bone resection. (H) After osteotomy, the frontal sinuses are temporarily exposed.

On the left palm was noted an unusual and irregular increase of connective tissue. The soft tissue hyperplasia caused some unusual wrinkling of the skin. This finding resembled the characteristic cerebriform skin surface increase known in Proteus syndrome. The fingers were regularly differentiated and functional. Figures 2 and 3 show some physical findings oft he patient.

We noted no characteristic nevi of the integument. The integumental findings were recorded on whole body photographs (not shown).

Computed tomography. A computed tomogram (CT) was performed to manufacture a three-dimensional skull model (Figure 1). Axial sectional skull images revealed massive hyperostosis, particularly of the frontal and occipital bones. On the right side there were soft tissue-equivalent opacities in mastoid cells indicating mastoiditis. Individual ethmoidal cells showed masses equivalent to soft tissues and were assessed as swelling of mucous membranes. Both external auditory canals were subtotally obstructed due to osseous overgrowth.

The cervical spine showed significant changes, which were interpreted as a further syndrome manifestation. Pronounced vertebral hyperplasia was displayed in the range from the foramen magnum down to vetrebrae C IV and C V, very pronounced in the arch roots. A noticeable left-sided hypertrophy of the uncovertebral joint was diagnosed in segment C III/C IV. This deformity resulted in stenosing the C IV root on the same side. There was also a central spinal stenosis at this level. However, the patient experienced no sensomotoric deficits in related organs. Figure 4 shows some skeletal findings of the patient.

Ultrasound. Normal-sized thyroid lobes were shown in Bscan ultrasonography of the neck, whereby internal signals of the organ were noticeably low. This ultrasound finding is characteristic of autoimmune hypothyroidism (permanent substitution with L-thyroxine $175 \mu \mathrm{g} / \mathrm{d}$ ). 

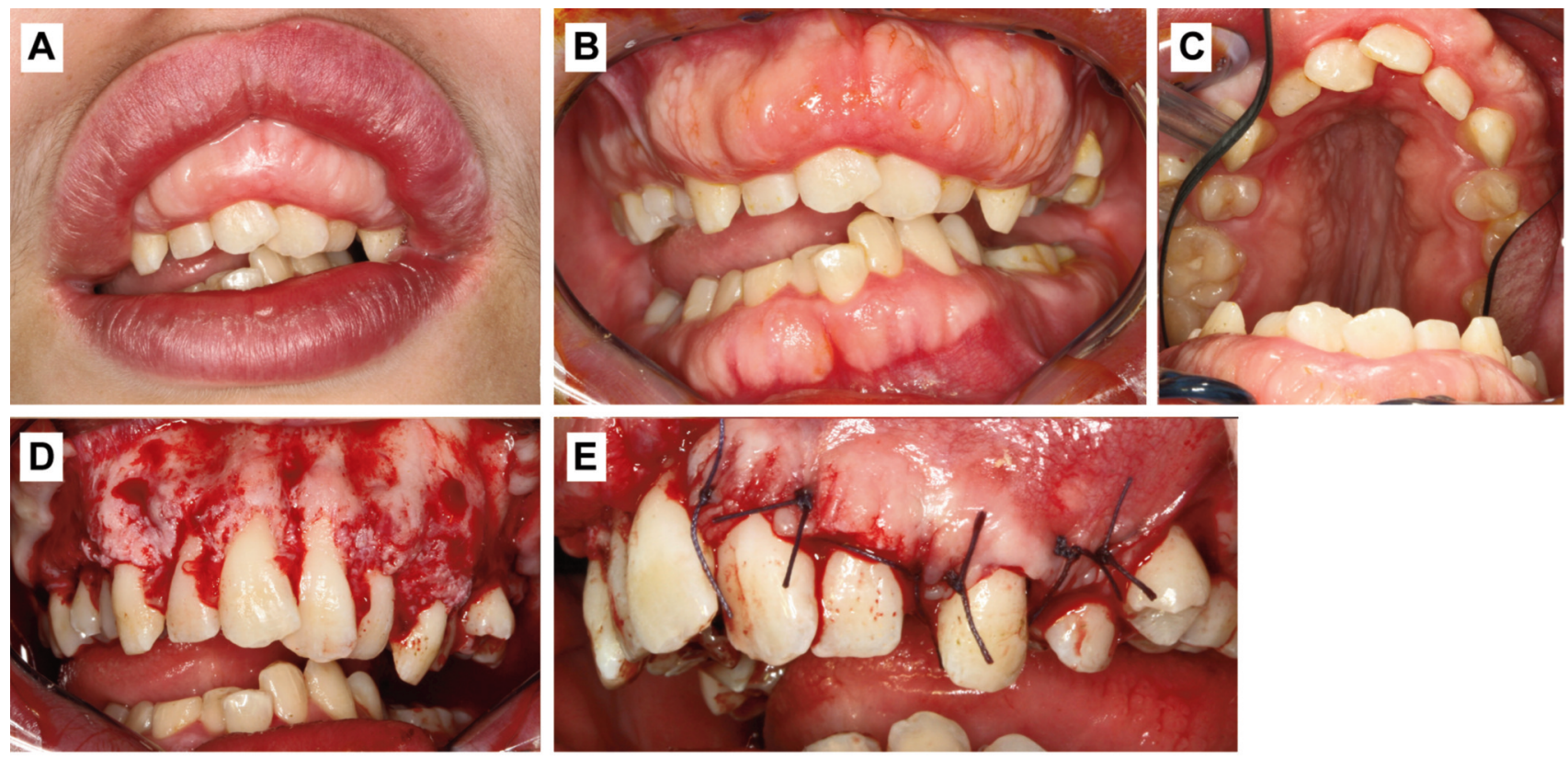

Figure 3. Oral findings of the patient with Proteus syndrome. (A) Open mouth at rest exposes mucosal hyperplasia of upper jaw. (B) Hyperplastic oral mucosa of both alveolar processes becomes apparent after lifting the lips. (C) The high-arched palate is not affected by the mucosal hyperplasia. (D) After lifting the тисоsa, the prominent formation of the alveolar processes becomes apparent. There is periodontal bone loss in individual teeth. (E) Oral aspect after thinning of the hyperplastic connective tissue of the oral mucosa and contouring of the gingiva at the junction between the tooth crown and the tooth root.

Treatment. Debulking the extensive bony overgrowth of the frontal region was performed in general anesthesia. The bicortical extent of frontal bone hyperplasia was about 20 $\mathrm{mm}$ (Figure 2), as could be predicted from the proportions of the skull model (Figure 1D). The frontal sinuses were opened during bone debulking (Figure $2 \mathrm{H}$ ). The defects were closed with bone chips and a galea-periosteal graft. Finally, the scalp was repositioned and fixed with sutures (Figure 2D). Wound healing was uneventful. One year later, the patient reappeared, this time to have removed the oral connective tissue hyperplasia, which caused both functional and aesthetic problems. In general anesthesia, vestibular pedicled mucoperiosteal flaps were raised and the alveolar processes exposed. The hyperplastic oral mucosa was thinned and the prominent undulating alveolar processes were modeled by leveling. Finally, the repositioned mucosa was contoured and fixed to the cementum-enamel border (Figure 3). Again, healing was uneventful.

Histology. The bones of the calvaria and the jaw were examined histologically. In both cases normal, lamellar bone was found with no evidence of inflammatory or dysplastic foci. The tissue samples of the oral mucosa revealed normal connective tissue with isolated nests of inflammatory cells.

Follow-up. The patient was satisfied with the oral and craniofacial treatment results and did not want further surgical interventions. The patient was examined again 7 years later in another hospital because she was experiencing it increasingly different to swallow and her oral food intake was severely hampered. Current $\mathrm{CT}$ and magnetic resonance images of the neck revealed osseous constricted cervical spinal canal (C IIIC VI) without evidence of myelon compression and no pathological myelon signal. However, the marked cervical lordosis and hypertrophic vertebral bodies were assessed to have an oropharyngeal mass effect.

Medical reports detail that she had a lockjaw at the time of inpatient admission for diagnosing causes of impaired food intake. Therefore, a transnasal endoscopy of the upper aerodigestive tracts was performed. Endoscopic examination showed significant external compression of the esophagus, possibly due to advanced anterior protrusion of cervical vertebrae. The mucous membranes of the esophagus were normal. Vascular malformations of the mucous membranes were not detected. The patient was recommended to have inserted a percutaneous gastric tube to secure gastrointestinal nutrition. Thereeafter, the patient was lost for further follow-up.

\section{Discussion}

This report describes a remarkable growth excess in skull, cervical spine and oral mucosa and presents related regional pathologies. Successful local surgical treatment alleviated the patient from some physical disfigurement. Both bone surgery 

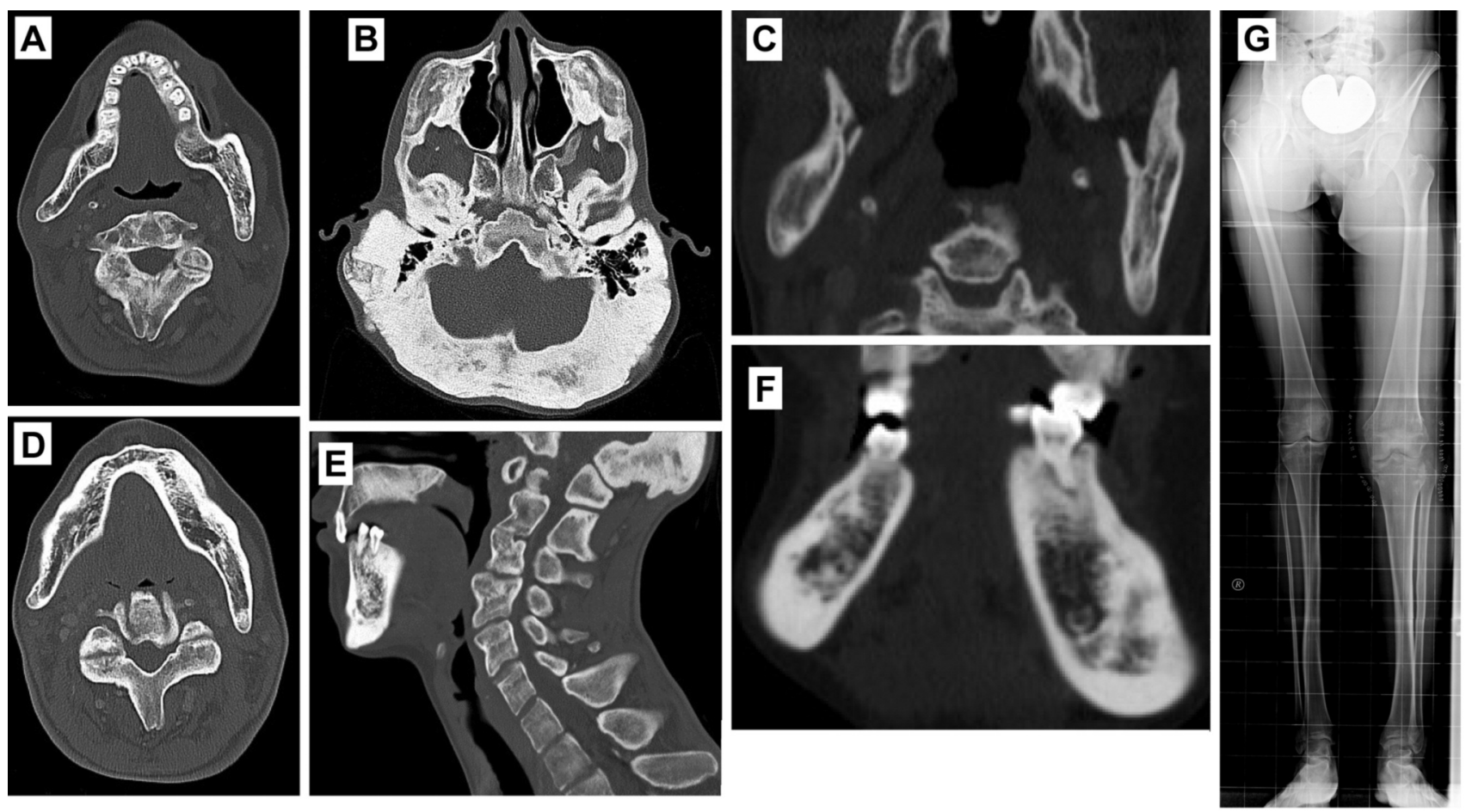

Figure 4. Radiological findings of the patient with Proteus syndrome in computed tomograms $(A-F)$ and plain radiograph $(G)$. (A) Asymmetrical and deforming hyperostosis of the mandible and cervical vertebral body (axial view). (B) Pronounced hyperostosis of the dorsal base of the skull and the zygomatico-maxillary complex. As shown in the $3 D$ model (Figure $1 B$ and D), the zygomatic arches are less affected by the hyperostosis than adjacent anterior and posterior bones. (C) Asymmetrically developed mandibular rami with differently developed mandibular foramina (coronal view). (D) The mandibular corpus is also developed asymmetrically, but the soft tissue coverage partially compensates for the asymmetry. The nerve canals are blurred (axial view). (E) Deformed and oropharyngeally protruding cervical vertebrae. Note the size ratio of the teeth to the surrounding jaw (sagittal view). (F) Asymmetrical mandibular body showing the mandibular canals. The canal on the left is significantly larger than on the right (coronal view). (G) Overview of the pelvis and lower extremities. The pelvis is inclined to the left side. The horizontal diameters of the long bones on the left are larger than those of the right.

and soft tissue modeling measures resulted in a permanent aesthetic and functional improvement in oral conditions and facial expression. However, as the disease progressed, local bone growth in the cervical spine probably led to severe impairment of oral nutrition.

Phenotype. Proteus syndrome is a progressive disorder that frequently comes to notice as asymmetric, dysproportionate overgrowth of tissues. The changes in size and shape typically arise shortly after birth of an apparently normally developed baby (16). The affected cells causing localized overgrowth may derive from any germline layer or combinations thereof. Somatic mutations arising early in ontogenesis are estimated to be the cause of the plethora of findings in Proteus syndrome (17). Progressive segmental overgrowth most commonly affects bones, skin, fat tissues, and central nervous system (18-27). Skeletal enlargements such as macrodactyly, vetrebral anomalies (scoliosis), and hyperostosis usually get noticed firsts $(1,2,8)$. However, asymmetric/dysproportionate development of vessels and muscles are also characteristic features of the syndrome as are visceral findings such as cystiform pulmonary abnormalities (4). Furthermore, both regions of hyperplasia and hypoplasia may be noted in the same individual $(28,29)$ indicating that local overgrowth is a visually noticeable epiphenomenon of fundamental disruptions of cellular differentiation and cell metabolism (30).

Frequency. The rare occurence of the disease and large differences in phenotype are major reasons why overviews of the phenotype were based on the evaluation of individual reports or case series small in number for long times $(1,4-$ $8,16,18,19)$. Only a few working groups report experience with diagnosis and therapy of Proteus syndrome based on larger numbers of cases $(26,31-33)$. Therefore, individual reports continue to help illustrate the phenotype and understand the disease. This assessment applies in particular to oral findings that have hardly been taken into account so far. However, the exclusion of cases previously erroneously diagnosed as Proteus syndrome in studies on overgrowth 
Table I. Historical scoring system to assess diagnostic features of Proteus syndrome. Minimum number of scoring points to diagnose Proteus syndrome is 13 [according to (5) and (7)].

\begin{tabular}{lcc}
\hline Feature & Points & Present case \\
\hline $\begin{array}{l}\text { Macrodactyly and/or hemihypertrophy } \\
\text { Skin thickening (plantar and/or palmar }\end{array}$ & 5 & Yes \\
cerebriform hyperplasia) & 4 & Yes \\
Lipomas and subcutaneous tumors & 4 & No \\
Verrucous epidermal nevus & 3 & No \\
Macrocephaly or skull exostoses & 2.5 & Yes \\
Miscellaneous minor abnormalities & 1 & Yes \\
Total & 19.5 & 12.5 \\
\hline
\end{tabular}

syndromes is necessary to date because the overlap of certain findings in Proteus syndrome and related syndromes influences the initial assessment of the patients $(18,34)$. Classification suggestions are helpful for assigning a patient to a syndromic disease (Tables I, II and III).

Classification. Several attempts have been made to establish diagnostic criteria in Proteus syndrome (4 -8). An earlier classification assigns a numerical value to various findings, the sum of which must be greater than 13 (Table I). According to this classification, the presented case does not fulfill the diagnostic criteria. However, this early classification does not go into the fact that excessive growth of adipose tissue is just as much a part of the phenotype as a pronounced lack of adipose tissue $(28,29)$. The patient is extremely thin. A more recent classification (Table II) divides the relevant findings according to their diagnostic value in one general and three specific categories $(8,16)$. The categories assess the patient on different levels of knowledge, for which the course of the disease, quality and topography of the findings have their own and differently important meanings. In this classification, the dominant general category gives the disease a diagnostic spatio-temporal frame. This general category addresses predominantly, but not exclusively, the skeleton. Findings are assessed according to the time of first notice (postnatal), biological behaviour (progressive growth), and topography (asymmetry of findings, disproportional growth). The first specifying category A represents a single finding, that is the unusual hyperplasia of the connective tissue, predominantly arising in the foot sole (8). In further explanation of the diagnostic criteria it is admitted that skin changes of this type can also occur in other parts of the body and used diagnostically, but are less frequently recorded $(16,31)$. Findings now known as cerebriform cutaneous tissue nevus (CCTN) were already listed as characteristic palmar features of the syndrome in 4 of 5 cases in a publication where the eponymous designation of the disease was introduced (4). These cutaneous signs were called CCTN because of the similarity between the affected skin and the surface of the exposed brain. Until recently, the "gyrated (skin) surfaces" (35) or "gyriform masses" (36) were so characteristic for Proteus syndrome that evidence of CCTN - in conjunction with the general category - was conclusive for clinical diagnosis of Proteus syndrome $(8,37)$. Current studies show this specificity of the finding is not valid (38). However, the recently announced limited diagnostic specificity does not affect the importance of the finding for orienting clinical examinations in the event of a suspected Proteus syndrome (39). CCTN is better assigned as connective tissue malformation (40) and was detected in $97 \%$ of cases (feet) and 28\% (hands), resp. (31). The categories B and $\mathrm{C}$ list several findings. However, findings in categories $\mathrm{B}$ and $\mathrm{C}$ only contribute to the diagnosis if all individual findings have been registered in the respective sub-category. According to this classification, the diagnosis of Proteus syndrome is dominated by fulfillment of the diagnostic criteria according to the general category and category A (16). Applied to the presented case, despite recording numerous groundbreaking findings in categories $\mathrm{B}$ and $\mathrm{C}$, the total number of individual findings does not fulfill all items of the sub-categories. However, category A criterion is met, and the general characteristics apply to the case.

Genetics. Prevalence of Proteus syndrome (Online Mendelian Inheritance in Man No. 176920) is estimated 1:1,000,000. However, some authors have expressed doubts about prevalence estimates because oligosymptomatic patients can escape diagnosis (41). Male-to-female ratio is 1.9:1. Proteus syndrome is a sporadic disease caused by somatic mutations $(15,17)$. It is assumed that Proteus syndrome belongs to the heterogeneous group of sporadic genetic diseases characterized by postzygotic mutations surviving by mosaicism, which, as germ cell mutations, are lethal $(42,43)$.

About $90 \%$ of cases carry a somatic activating mutation (c.49G $\rightarrow$ A,p.Glu17Lys) in the oncogene AK strain transforming 1 [(AKT1), cytogenetic location: 14q32.33], encoding the AKT1 kinase (previously used synonymon: RAC-alpha serine/threonine-protein kinase). AKT1 is an enzyme known to mediate cell proliferation and apoptosis $(16,44)$. However, it has not been yet possible to establish a correlation between the mutation status of the tissue and the lesions in the syndrome (45). Recent studies show allelic heterogeneity of Proteus syndrome in AKT1 mutations, so lack of evidence of the characteristic mutation should no longer be interpreted as an exclusion diagnosis in a potential case of Proteus syndrome (46). The patient's genetic status was not examined because the patient had been treated before the characteristic mutation was identified.

Skull. The local osseous overgrowths should be described as 'hyperostosis' not as exostosis or osteoma (8). However, the 
Table II. Current clinical diagnostic criteria to establish Proteus syndrome diagnosis [according to (16)]*.

\begin{tabular}{|c|c|c|c|}
\hline $\begin{array}{l}\text { General criteria } \\
\text { (Mandatory) }\end{array}$ & Category A & Category B & Category $\mathrm{C}$ \\
\hline $\begin{array}{l}\text { Mosaic distribution } \\
\text { of lesions }\end{array}$ & $\begin{array}{l}\text { Cerebriform connective } \\
\text { tissue nevus (CCTN) }\end{array}$ & Linear epidermal nevus & $\begin{array}{l}\text { Dysregulated adipose tissue } \\
\text { (either of the following): } \\
\text { Lipomatous overgrowth and/or } \\
\text { Regional lipoatrophy }\end{array}$ \\
\hline Sporadic occurrence & & $\begin{array}{l}\text { Asymmetric, disproportionate } \\
\text { overgrowth** ( } \geq 1 \text { of the following): } \\
\text { Limbs } \\
\text { Hyperostosis of the skull } \\
\text { Hyperostosis of the external auditory canal } \\
\text { Megaspondylodysplasia } \\
\text { (i.e., abnormal growth of vertebrae) } \\
\text { Viscera: spleen/thymus }\end{array}$ & $\begin{array}{l}\text { Vascular malformations } \\
\text { (one of the following): } \\
\text { Capillary malformation } \\
\text { Venous malformation } \\
\text { Lymphatic malformation } \\
\text { Bullous pulmonary degeneration }\end{array}$ \\
\hline Progressive course & & $\begin{array}{l}\text { Specific tumors with onset before the } \\
\text { second decade (either of the following): } \\
\text { Bilateral ovarian cystadenoma } \\
\text { Parotid monomorphic adenoma }\end{array}$ & $\begin{array}{l}\text { Facial phenotype } \\
\text { (all of the following): } \\
\text { Dolichocephaly } \\
\text { Long face } \\
\text { Downslanting palpebral fissures } \\
\text { and/or minor ptosis } \\
\text { Depressed nasal bridge } \\
\text { Wide or anteverted nares } \\
\text { Open mouth at rest }\end{array}$ \\
\hline
\end{tabular}

*For clinical diagnosis of Proteus syndrome, the following combinations of findings are the minimum: ALL of the general criteria AND specific criteria from categories A-C: One from category A, OR two from category B, OR three from category C. **The authors of the classification emphasize that asymmetric, disproportionate overgrowth should be carefully distinguished from asymmetric, proportionate, or ballooning overgrowth.

term 'exostosis' is still used for these bone changes (Tables I and III) (47). Modeling osteotomy is an essential tool for reducing the facial disfigurement caused by excessive bone growth. Approaches and osteotomy techniques are based on the principles of craniofacial surgery. In the presented case, noticeable protrusions of the bone had to be corrected. The overall increased skull growth and its effects on the facial type were not influenced by the measure.

Craniofacial bone reduction. The use of removed bone to contour the calvaria is not recommended because it is suspected the reuse of the lesion bone increases the risk of recurrence. If the removal of calvarial bone leads to defects, intact bone regions should be selected as the donor region (13). In the present case, chips of resected bone segments were used to cover the opened roof of frotal sinuses. During the observation interval, there was no recurrence of excessive bone growth in the contoured frontal region. However, the recipient site of the osteoplasty consisted of the residual bone that had given rise to the excessive and disfiguring skelettal growth.

Skin. Skin findings are important in diagnosing the syndrome. Linear lesions of an epidermal nevus, teleangiectatic nevi or vascular lesions were recorded in more than $60 \%$ to $88 \%$ of cases (26) and can be very pronounced (47). Hyperplasia of connective tissues of feet soles is considered a hallmark of Proteus syndrome (see "classification"). The lesion is variable in size and may create a localized cushion-like excess of soft tissue (17). Also called "moccasin" lesions (17), the frequent but not obligatory finding arises uni- or bilaterally (31). Development of lipoma is recorded in about 9 of 10 affected individuals $(26,31)$. On the contrary, dermal hypoplasia was recorded in $22 \%$ of patients (31).

Oral soft tissue. While malformations and tumors of the skin in Proteus syndrome have been described more frequently, oral manifestations have been noted only rarely. For example, dental manifestations of Proteus syndrome are not mentioned in a detailed review on diagnosis of oral findings of syndromic rare diseases with craniofacial manifestations (48). Gingival hyperplasia was noted by Arendorf and Henslo (49). In their case, local soft tissue overgrowth had covered several maxillary teeth. Gingivectomy was performed and permanently achieved both contouring of the gingiva and occlusal contact of teeth. Histological examination confirmed regular epithelial differentiation with mature bundles of collagenous fibres. Clusters of fibroblasts and chronic inflammatory cells were embedded in the connective tissue (49). Another report describes unilateral muco-gingival hyperplasia of the mandible. Biopsy of the oral soft tissue revealed fibromatosis gingivae (50). Obviously, soft tissue findings of the oral cavity are rarely 
Table III. Literature review of Munhoz et al. (32) on oral and maxillofacial findings in Proteus syndrome derived from 14 cases. Findings observed in the presented case are highlighted in bold.

\begin{tabular}{|c|c|c|}
\hline Extraoral findings & Intraoral findings & Imaging findings \\
\hline Epidermal nevus & Impacted teeth & Panoramic radiography: \\
\hline Hemifacial/specific bone hypertrophy & $\begin{array}{l}\text { Malocclusion (i.e.: dental crowding, } \\
\text { dental rotation, asymmetric occlusion) }\end{array}$ & $\begin{array}{l}\text { - Dental agenesis and/or ectopia, impacted } \\
\text { teeth, roots dilacerated and/or resorption }\end{array}$ \\
\hline Craniofacial asymmetry & Dental ectopia & - Mandibular hemihypertrophy \\
\hline Presence of exostoses & Asymmetric enamel hypoplasia & $\begin{array}{l}\text { - Enlargement of mandibular canal**, mandible } \\
\text { body**, ramus, condyle**, mental foramen* } \\
\text { - Asymmetric dental growth and maturation }\end{array}$ \\
\hline Mandibular retrusion or prognathism & Teeth agenesis & $\begin{array}{l}\text { Computed tomography: } \\
\text { - Degenerative changes or enlargement of }\end{array}$ \\
\hline Open mouth at rest & $\begin{array}{l}\text { Shape changes in hard palate, } \\
\text { mandible, maxilla }\end{array}$ & $\begin{array}{l}\text { the temporomandibular joint } \\
\text { Exostosis }\end{array}$ \\
\hline Long face & Asymmetric macroglossia & Lateral cephalometric radiograph \\
\hline Hypertelorism & Exostosis, osteoma & $\begin{array}{l}\text { - Prognathism or retrognathism } \\
\text { (Maxilla and/or mandible) } \\
\text { - Vertebral enlargement* }\end{array}$ \\
\hline Macrocephaly & $\begin{array}{l}\text { Midline deviation } \\
\text { Unusual frenula }\end{array}$ & $\begin{array}{l}\text { Magnetic resonance imaging } \\
\text { - Fibrofatty facial mass infiltration } \\
\text { - Primary expansion of bone marrow } \\
\text { and bone hypertrophy* } \\
\text { - Hyperostosis* }\end{array}$ \\
\hline
\end{tabular}

*Findings revealed on $\mathrm{CT}$ and identified on skull model. **Unilateral or asymmetric.

noted in patients with Proteus syndrome. For example, the detailed analysis of oral findings in the case of significant hyperplasia and deformation of the calvarial and facial bones revealed malocclusal of teeth and tooth root resorption but no hyperplasia of the gingiva (35). A systematic review of published data on maxillofacial manifestations of Proteus syndrome with special consideration of oral manifestations (32) (Table III) describes gingival hyperplasia in only two cases (49, 50) based on 14 studies used for this evaluation. This overview can be supplemented by further two reports on gingival hyperplasia in Proteus syndrome $(36,51)$. However, no histological findings are detailed in either report.

Further observations refer to unusually high-set frenula, which can cause diastema mediale or develop bifid (47). There are also individual reports of unilateral hyperplasia of the tongue $(21,51,52)$.

Teeth. Occasionally, the patient's teeth are conspicuous due to crowding of occlusion disorders. Teeth in Proteus syndrome are usually of normal size (49), an important difference to hemifacial hyperplasia patients who often have macrodontia (52). Tooth development can be influenced in unilaterally affected jaw sections, so a comparison of the jaw sides may show different stages of development (35). The different sizes within a jaw can cause considerable vertical difference in the occlusal plane between affected and unaffected jaw sections (52). In the presented case, the incorrect occlusion of the rows of teeth was associated with an asymmetrically developed bilateral and bimaxillary hyperostosis. Other reports detail enamel hypoplasia (53, 54). Tooth retentions are described for patients with Proteus syndrome, as well as agenesis of teeth (32). In summary, the reports on dental findings in Proteus syndrome are rare and so far, findings are not specific (32).

Jaws. Hyperplasia of the jaws is usually unilateral in Proteus syndrome $(3,12,51)$. Skelettal overgrowth can affect the entire side of one or both jaws or only sections of the respective bone, for example the condylar process $(51,52$, $55,56)$. Functionally effective, symmetric underdevelopment of the mandibular corpus was also reported (57). In the present case, both jaws are substantially oversized and slightly asymmetrical. The soft tissues proportionally cover the bone and extends evenly in regions with hyperostosis. The association of soft tissue excess, e.g. CCTN, and skeletal hyperplasia and/or deformity is characteristic in the distal contact areas of extremities in Proteus syndrome (14), but is not a frequent sign in the skull. For example, oropharyngeal soft tissue hyperplasia developed without hyperplasia of the adjacent facial bone (36).

In the present case, the palate was high arched. High arched palate is a frequent finding in several syndromes. High arched palate can be missing in patients with jaw overgrowth $(51,52)$. Open bite is a rare finding independent of dental crowding (52, 57). Enlargement of inferior alveolar nerve and mandibular canal was noted in Proteus syndrome (52). However, an 
enlarged mandibular nerve canal on plain skull X-ray or CT is not proof of an enlarged nerve. Enlarged mandibular canals have been demonstrated for other syndromes, particularly in patients with neurofibromatosis type 1 (NF1) (58).

Localized bone growth was observed in the alveolar process of the mandible (3). However, these bone findings were addressed as alveolar 'exostoses' (3), while in the present case the alveolar processes appear proportionally enlarged or vestibularly protruded.

In the further course the patient had apparently experienced considerable restrictions in opening the lower jaw. These findings were only known from a later medical report. A cause for the functional impairment is not known. Restricted mouth opening without evidence of a causal skeletal condition has been reported occasionally (32). A maxillary tumor of unknown origin in the left maxilla was reported (35) and a case with teeth agenesis and odontogenic fibroma (47). The detection of AKT1 mutation in a dental cyst of a Proteus patient proved first evidence of association between the disfiguring disease and an oral dysontogenetic finding (47).

Spine and swallowing disorder. Deformations of the spine as a whole and deformations and enlargements of one or more vertebral bodies belong to the skeletal phenotype of Proteus syndrome (59). Orthopedic surgical measures are necessary in cases, for example, when spinal compressions lead to functional failures (60). In the case presented, the deformed and enlarged cervical spine did not have any functional impairment of the swallowing function during the craniomaxillofacial surgery phase. The reported significant swallowing disorder did not occur until several years later. The cause of the swallowing disorder was suspected to be the progressive growth of the vertebral bodies with compression of the esophagus. However, soft tissue masses can make speaking and swallowing difficult and require surgical intervention $(36,61)$.

Further rare findings in present case. The patient has some findings that have been rarely or not at all reported in connection with Proteus syndrome.

Diabetes mellitus. The patient developed type I diabetic mellitus. The association of Proteus syndrome and diabetes is not listed in reviews on the syndrome (16), nor in more recent papers based on the genetic characterization of AKT1 mutation in the disease (46). Syndromal associations with diabetes mellitus have been described for mutations of the AKT2 gene (62). Polyuria in Proteus syndrome was reported occasionally (6).

Likewise, Hashimoto thyroiditis is not a feature that is included in the plethora of the Proteus syndrome findings. Association of Hashimoto thyroiditis with syndromes has been reported on various occasions, for example in Bannayan-Riley-Ruvalcaba syndrome (63) or in NF1 (64).
The hyperostosis of the external auditory canal is considered rare in Proteus syndrome (9). However, the evidence of this ossification disorder in patients is an important indicator to confirm the suspicion in candidates of Proteus syndrome diagnosis $(3,9)$.

The influence of the disease on the skeletal system causes characteristic localized disproportionate growth of single or multiple bones. However, height attainment of patients with Proteus syndrome is usually normal (9). The patient's bones have grown disproportionately at several sites. She had several orthopedic operations to correct skeletal disproportions of the hip and lower extremity. The measures apparently resulted in a shortening of the lower left extremity, which was mainly affected by overgrowth. However, the patient has grown unusually tall. It can be assumed that this unusual height is related to the underlying disease. However, no further endocrinological examinations were carried out during the surgical therapy in order to rule out defined causes of skeletal growth errors. Above average growth has occasionally been reported in patients with Proteus syndrome (13).

Proteus syndrome and NF1. In the scientific-historical discussion of the Proteus syndrome, the distinction from NF1 is of particular importance because for many years the socalled elephant man had been diagnosed as suffering from neurofibromatosis (5). By re-evaluating known findings, Tibbles and Cohen (65) and Cohen (2) have identified the Proteus syndrome as very likely the diagnosis of this historical case. Reliable diagnostic criteria were defined in consensus for diagnosing NF1, which, with some modifications and corrections, have withstood the test of time (66). In addition, NF1 is an autosomal dominant hereditary disease, the gene locus of which is known and can be determined in over $90 \%$ of cases (67). The present patient did not have any of the stigmata of integument that guide the diagnosis of NF1 (66). The application of strict diagnostic criteria to classify a patient with Proteus syndrome is essential. Failure to consider the minimal spectrum of accepted diagnostic findings (9) can lead to erroneously or at least unfounded application of the diagnosis $(3,21,26,33,43)$.

\section{Conclusion}

Proteus syndrome is a disease that can affect many organs and regions of the body. In the case of skeletal overgrowth, surgical measures can reduce the degree of disability and alleviate the symptoms in individual cases. Oral findings associated with the disease have so far been rarely reported in Proteus syndrome. Conspicuous oral soft tissue overgrowths can cause functional and aesthetic impairments that can at least partially be treated surgically. The application of local measures must consider that many patients have to 
struggle with consequences of their genetic disposition that lie outside the respective therapeutic field (68). As can be seen in the presented case, the general diagnostic criteria (16), in particular the progressive course of the disease, are a decisive factor in the patient's quality of life (68).

\section{Conflicts of Interest}

The Author states that there are no conflicts of interest regarding the publication of the study.

\section{Acknowledgements}

This research did not receive any specific grant from funding agencies in the public, commercial, or not-for-profit sectors.

\section{References}

1 Cohen MM Jr and Hayden PW: A newly recognized hamartomatous syndrome. Birth Defects Orig Artic Ser 15(5B): 291-296, 1979. PMID: 118782.

2 Cohen MM Jr: Understanding Proteus syndrome, unmasking the elephant man, and stemming elephant fever. Neurofibromatosis 1(5-6): 260-280, 1988. PMID: 3152479.

3 Smeets E, Fryns JP and Cohen MM Jr: Regional Proteus syndrome and somatic mosaicism. Am J Med Genet 51(1): 2931, 1994. PMID: 8030665. DOI: 10.1002/ajmg.1320510107

4 Wiedemann HR, Burgio GR, Aldenhoff P, Kunze J, Kaufmann HJ and Schirg E: The Proteus syndrome. Partial gigantism of the hands and/or feet, nevi, hemihypertrophy, subcutaneous tumors, macrocephaly or other skull anomalies and possible accelerated growth and visceral affections. Eur J Pediatr 140(1): 5-12, 1983. PMID: 6873112. DOI: 10.1007/BF00661895

5 Hotamisligil GS: Proteus syndrome and neurofibromatosis. Neurofibromatosis 2(5-6): 339-340, 1989. PMID: 2518518.

6 Hotamisligil GS and Ertogan F: The Proteus syndrome: Association with nephrogenic diabetes insipidus. Clin Genet 38(2): 139-144, 1990. PMID: 2208765. DOI: 10.1111/j.1399-0004.1990.tb03562.x

7 Darmstadt GL and Lane AT: Proteus syndrome. Pediatr Dermatol 11(3): 222-226, 1994. PMID: 7971556. DOI: 10.1111/j.15251470.1994.tb00590.x

8 Biesecker LG, Peters KF, Darling TN, Choyke P, Hill S, Schimke $\mathrm{N}$, Cunningham M, Meltzer P and Cohen MM Jr: Clinical differentiation between Proteus syndrome and hemihyperplasia: Description of a distinct form of hemihyperplasia. Am J Med Genet 79(4): 311-318, 1998. PMID: 9781913. DOI: 10.1002/ (sici)1096-8628(19981002)79:4<311::aid-ajmg14>3.0.co;2-u

9 Biesecker LG, Happle R, Mulliken JB, Weksberg R, Graham JM Jr, Viljoen DL and Cohen MM Jr: Proteus syndrome: Diagnostic criteria, differential diagnosis, and patient evaluation. Am J Med Genet 84(5): 389-395, 1999. PMID: 10360391. DOI: 10.1002/ (sici)1096-8628(19990611)84:5<389::aid-ajmg1>3.0.co;2-o

10 Biesecker L: The challenges of Proteus syndrome: Diagnosis and management. Eur J Hum Genet 14(11): 1151-1157, 2006. PMID: 16883308. DOI: $10.1038 /$ sj.ejhg. 5201638

11 Stricker S: Musculoskeletal manifestations of Proteus syndrome: Report of two cases with literature review. J Pediatr Orthop 12(5): 667-674, 1992. PMID: 1517432.
12 Adolphs N, Tinschert S, Bier J and Klein M: Craniofacial hyperostoses in Proteus syndrome - a case report. J Craniomaxillofac Surg 32(6): 391-394, 2004. PMID: 15555524. DOI: $10.1016 /$ j.jcms.2004.06.007

13 Sakamoto Y, Nakajima H, Kishi K, Shimizu R and Nakajima T: Management of craniofacial hyperostosis in Proteus syndrome. J Craniofac Surg 21(2): 414-418, 2010. PMID: 20216456. DOI: $10.1097 / \mathrm{SCS} .0 \mathrm{~b} 013 \mathrm{e} 3181 \mathrm{cfa} 7 \mathrm{f0}$

14 Taghinia AH, Mulliken JB and Rogers GF: A case of Proteus syndrome with lateral embryonal vein and frontal intraosseous lipoma. Cleft Palate Craniofac J 44(5): 567-571, 2007. PMID: 17760489. DOI: 10.1597/06-141.1

15 Cohen MM Jr: Proteus syndrome: An update. Am J Med Genet C Semin Med Genet 137C(1): 38-52, 2005. PMID: 16010681. DOI: 10.1002/ajmg.c.30063

16 Biesecker LG, Sapp JC, Adam MP, Ardinger HH, Pagon RA, Wallace SE, Bean LJH, Mirzaa G and Amemiya A: Proteus Syndrome: 2019. PMID: 22876373.

17 Cohen MM Jr: Proteus syndrome: Clinical evidence for somatic mosaicism and selective review. Am J Med Genet 47(5): 645652, 1993. PMID: 8266991. DOI: 10.1002/ajmg.1320470514

18 Alves C, Acosta AX and Toralles MB: Proteus syndrome: Clinical diagnosis of a series of cases. Indian $\mathrm{J}$ Endocrinol Metab 17(6): 1053-1056, 2013. PMID: 24381883. DOI: $10.4103 / 2230-8210.122621$

19 Angurana SK, Angurana RS, Panigrahi I and Marwaha RK: Proteus syndrome: Clinical profile of six patients and review of literature. Indian J Hum Genet 19(2): 202-206, 2013. PMID: 24019623. DOI: $10.4103 / 0971-6866.116117$

20 Badia MC, Chamarro R, Làinez JM and Piera A: [Proteus syndrome with cerebral vascular malformations]. Neurologia 21(2): 88-91, 2006. PMID: 16525914.

21 DeLone DR, Brown WD and Gentry LR: Proteus syndrome: Craniofacial and cerebral MRI. Neuroradiology 41(11): 840-843, 1999. PMID: 10602859. DOI: 10.1007/s002340050853

22 Di Stefani A, Gabellini M, Ferlosio A, Spagnoli LG, Chimenti S and Orlandi A: Cerebriform plantar hyperplasia: The clinico-pathological hallmark of Proteus syndrome. Acta Derm Venereol 91(5): 580-581, 2011. PMID: 21681363. DOI: 10.2340/00015555-1087

23 Dietrich RB, Glidden DE, Roth GM, Martin RA and Demo DS: The Proteus syndrome: CNS manifestations. AJNR Am J Neuroradiol 19(5): 987-990, 1998. PMID: 9613526.

24 Sarnat HB, Diadori P and Trevenen CL: Myopathy of the Proteus syndrome: Hypothesis of muscular dysgenesis. Neuromuscul Disord 3(4): 293-301, 1993. PMID: 8268726. DOI: 10.1016/0960-8966(93)90022-c

25 Pazzaglia UE, Beluffi G, Bonaspetti G and Ranchetti F: Bone malformations in Proteus syndrome: An analysis of bone structural changes and their evolution during growth. Pediatr Radiol 37(8): 829-835, 2007. PMID: 17569038. DOI: 10.1007/ s00247-007-0486-1

26 Nguyen D, Turner JT, Olsen C, Biesecker LG and Darling TN: Cutaneous manifestations of proteus syndrome: correlations with general clinical severity. Arch Dermatol 140(8): 947-953, 2004. PMID: 15313810. DOI: 10.1001/archderm.140.8.947

27 Guidera KJ, Brinker MR, Kousseff BG, Helal AA, Pugh LI, Ganey TM and Ogden JA: Overgrowth management in KlippelTrenaunay-Weber and Proteus syndromes. J Pediatr Orthop 13(4): 459-466, 1993. PMID: 8396594. DOI: 10.1097/012413 98-199307000-00009 
28 Happle R: Elattoproteus syndrome: delineation of an inverse form of Proteus syndrome. Am J Med Genet 84(1): 25-28, 1999. PMID: 10213042. DOI: 10.1002/(sici)1096-8628(19990507)84: $1<25$ ::aid-ajmg6>3.0.co; 2 -f

29 Happle R: The manifold faces of Proteus syndrome. Arch Dermatol 140(8): 1001-1002, 2004. PMID: 15313819. DOI: 10.1001/archderm.140.8.1001

30 Nathan N, Keppler-Noreuil KM, Biesecker LG, Moss J and Darling TN: Mosaic disorders of the PI3K/PTEN/AKT/TSC/ mTORC1 signaling pathway. Dermatol Clin 35(1): 51-60, 2017. PMID: 27890237. DOI: 10.1016/j.det.2016.07.001

31 Beachkofsky TM, Sapp JC, Biesecker LG and Darling TN: Progressive overgrowth of the cerebriform connective tissue nevus in patients with Proteus syndrome. J Am Acad Dermatol 63(5): 799-804, 2010. PMID: 20709429. DOI: 10.1016/ j.jaad.2009.12.012

32 Munhoz L, Arita ES, Nishimura DA and Watanabe PCA: Maxillofacial manifestations of Proteus syndrome: A systematic review with a case report. Oral Radiol 37(1): 2-12, 2021. PMID: 31734933. DOI: 10.1007/s11282-019-00416-y

33 Turner JT, Cohen MM Jr and Biesecker LG: Reassessment of the Proteus syndrome literature: application of diagnostic criteria to published cases. Am J Med Genet A 130A(2): 111-122, 2004. PMID: 15372514. DOI: 10.1002/ajmg.a.30327

34 Lublin M, Schwartzentruber DJ, Lukish J, Chester C, Biesecker LG and Newman KD: Principles for the surgical management of patients with Proteus syndrome and patients with overgrowth not meeting Proteus criteria. J Pediatr Surg 37(7): 1013-1020, 2002. PMID: 12077761. DOI: 10.1053/jpsu.2002.33832

35 Korbmacher $\mathrm{H}$, Tietke $\mathrm{M}$, Rother $\mathrm{U}$ and Kahl-Nieke B: Dentomaxillofacial imaging in Proteus syndrome. Dentomaxillofac Radiol 34(4): 251-255, 2005. PMID: 15961602. DOI: 10.1259/ $\mathrm{dmfr} / 22554007$

36 Sahni JK, Kumar S, Wadhwa V and Kathuria G: Proteus syndrome with huge tonsillar mass causing dysphagia: A rare case. J Laryngol Otol 120(5): 408-410, 2006. PMID: 16556346. DOI: $10.1017 / \mathrm{S} 0022215106000430$

37 Uller W, Fishman SJ and Alomari AI: Overgrowth syndromes with complex vascular anomalies. Semin Pediatr Surg 23(4): 208-215, 2014. PMID: 25241100. DOI: 10.1053/j.sempedsurg. 2014.06.013

38 Keppler-Noreuil KM, Burton-Akright J, Lindhurst MJ, Shwetar J, Sapp JC, Darling $\mathrm{T}$ and Biesecker LG: Molecular heterogeneity of the cerebriform connective tissue nevus in mosaic overgrowth syndromes. Cold Spring Harb Mol Case Stud 5(4): 2019. PMID: 31371346 . DOI: $10.1101 / \mathrm{mcs} . a 004036$

39 Almeida HL Jr, Fiss RC and Happle R: Macrodactyly with skin hypertrophy: A minimal form of the Proteus syndrome. An Bras Dermatol 86(3): 557-559, 2011. PMID: 21738976. DOI: 10.1590/s0365-05962011000300021

40 Happle R: Mosaicism in Human Skin. Springer, Berlin Heidelberg, p. 131, 2014.

41 Morelli F, Feliciani C, Toto P, De Benedetto A and Tulli A: A minimal form of Proteus syndrome presenting with macrodactyly and hand hyperplasia. Eur J Dermatol 13(2): 196198, 2003. PMID: 12695139.

42 Happle R: Lethal genes surviving by mosaicism: A possible explanation for sporadic birth defects involving the skin. J Am Acad Dermatol 16(4): 899-906, 1987. PMID: 3033033. DOI: $10.1016 / \mathrm{s} 0190-9622(87) 80249-9$
43 Happle R: The categories of cutaneous mosaicism: A proposed classification. Am J Med Genet A 170A(2): 452-459, 2016. PMID: 26494396. DOI: 10.1002/ajmg.a.37439

44 Lindhurst MJ, Sapp JC, Teer JK, Johnston JJ, Finn EM, Peters K, Turner J, Cannons JL, Bick D, Blakemore L, Blumhorst C, Brockmann K, Calder P, Cherman N, Deardorff MA, Everman DB, Golas G, Greenstein RM, Kato BM, Keppler-Noreuil KM, Kuznetsov SA, Miyamoto RT, Newman K, Ng D, O’Brien K, Rothenberg S, Schwartzentruber DJ, Singhal V, Tirabosco R, Upton J, Wientroub S, Zackai EH, Hoag K, Whitewood-Neal T, Robey PG, Schwartzberg PL, Darling TN, Tosi LL, Mullikin JC and Biesecker LG: A mosaic activating mutation in AKT1 associated with the Proteus syndrome. N Engl J Med 365(7): 611619, 2011. PMID: 21793738. DOI: 10.1056/NEJMoa1104017

45 Doucet ME, Bloomhardt HM, Moroz K, Lindhurst MJ and Biesecker LG: Lack of mutation-histopathology correlation in a patient with Proteus syndrome. Am J Med Genet A 170(6): 1422-1432, 2016. PMID: 27112325. DOI: 10.1002/ajmg.a.37612

46 Buser A, Lindhurst MJ, Kondolf HC, Yourick MR, KepplerNoreuil KM, Sapp JC and Biesecker LG: Allelic heterogeneity of Proteus syndrome. Cold Spring Harb Mol Case Stud 6(3): 2020. PMID: 32327430. DOI: 10.1101/mcs.a005181

47 Valéra MC, Vaysse F, Bieth E, Longy M, Cances C and BailleulForestier I: Proteus syndrome: Report of a case with AKT1 mutation in a dental cyst. Eur J Med Genet 58(5): 300-304, 2015. PMID: 25782637. DOI: 10.1016/j.ejmg.2015.02.008

48 Luo E, Liu H, Zhao Q, Shi B and Chen Q: Dental-craniofacial manifestation and treatment of rare diseases. Int J Oral Sci 11(1): 9, 2019. PMID: 30783081. DOI: 10.1038/s41368-018-0041-y

49 Arendorf TM and Hanslo B: Proteus syndrome: Association with gingival hyperplasia. J Oral Pathol Med 24(8): 383-384, 1995. PMID: 7500296. DOI: 10.1111/j.1600-0714.1995.tb01204.x

50 Rao GS and Vohra D: Proteus syndrome with gingival hyperplasia. Int J Dermatol 42(10): 826-828, 2003. PMID: 14521702. DOI: 10.1046/j.1365-4362.2003.01866.x

51 Yilmaz E, Kansu O, Ozgen B, Akçiçek G and Kansu H: Radiographic manifestations of the temporomandibular joint in a case of Proteus syndrome. Dentomaxillofac Radiol 42(2): 58444855, 2013. PMID: 22241876. DOI: $10.1259 / \mathrm{dmfr} / 58444855$

52 Becktor KB, Becktor JP, Karnes PS and Keller EE: Craniofacial and dental manifestations of Proteus syndrome: a case report. Cleft Palate Craniofac J 39(2): 233-245, 2002. PMID: 11879083. DOI: 10.1597/1545-1569_2002_039_0233_cadmop_2.0.co_2

53 Mason $\mathrm{C}$ and Roberts G: Unusual distribution of enamel hypoplasia in an 11-year-old child with Proteus syndrome. Int J Paediatr Dent 5(2): 103-107, 1995. PMID: 7547812. DOI: 10.1111/j.1365-263x.1995.tb00172.x

54 Canabarro A Jr, Galheigo TM, Galheigo de Oliveira e Silva D and Tinoco EM: Periodontal findings and other oral manifestations in Proteus syndrome: A case report. Quintessence Int 39(4): 307-311, 2008. PMID: 19081899.

55 Pinto PX, Beale V and Paterson AW: Proteus syndrome. A case report of a hamartomatous syndrome with severe mandibular hemihypertrophy. Oral Surg Oral Med Oral Pathol Oral Radiol Endod 85(1): 82-85, 1998. PMID: 9474620. DOI: 10.1016/ s1079-2104(98)90403-6

56 Tattelbaum AG and Dufresne CR: Proteus syndrome: A newly recognized hamartomatous syndrome with significant craniofacial dysmorphology. J Craniofac Surg 6(2): 151-160, 1995. PMID: 8601022. 
57 Nogueira RL, Teixeira RC, Lima MC, Sant'ana E and Santos $\mathrm{CF}$ : Apnoea-hypopnoea and mandibular retrusion as uncommon findings associated with Proteus syndrome. Dentomaxillofac Radiol 36(6): 367-371, 2007. PMID: 17699709. DOI: 10.1259/ $\mathrm{dmfr} / 42508276$

58 Visnapuu V, Peltonen S, Tammisalo T, Peltonen J and Happonen RP: Radiographic findings in the jaws of patients with neurofibromatosis 1. J Oral Maxillofac Surg 70(6): 1351-1357, 2012. PMID: 21856061. DOI: 10.1016/j.joms.2011.06.204

59 Kaiser R, Rothenfluh E, Rothenfluh D, Behrbalk E, Perez Romera AB, Stokes OM and Mehdian H: Surgical correction of kyphotic deformity in a patient with Proteus syndrome. Spine J 15(7): e5-e12, 2015. PMID: 25862503. DOI: 10.1016/j.spinee. 2015.04.008

60 Tosi LL, Sapp JC, Allen ES, O'Keefe RJ and Biesecker LG: Assessment and management of the orthopedic and other complications of Proteus syndrome. J Child Orthop 5(5): 319327, 2011. PMID: 23024722. DOI: 10.1007/s11832-011-0350-6

61 Zingade ND and Zingade NN: A rare case of Proteus syndrome. J Laryngol Otol 122(3): e7, 2008. PMID: 18279570. DOI: $10.1017 /$ S002221510700151X

62 Cohen MM Jr: The AKT genes and their roles in various disorders. Am J Med Genet A 161A(12): 2931-2937, 2013. PMID: 24039187. DOI: 10.1002/ajmg.a.36101

63 Gorlin RJ, Cohen MM Jr, Condon LM and Burke BA: Bannayan-Riley-Ruvalcaba syndrome. Am J Med Genet 44(3): 307-314, 1992. PMID: 1336932. DOI: 10.1002/ajmg. 1320440309
64 Friedrich RE, Grob TJ, Hollants S, Zustin J, Spaepen M, Mautner VF, Luebke AM, Hagel C, Legius E and Brems H: Recurrent multilocular mandibular giant cell granuloma in neurofibromatosis type 1: Evidence for second hit mutation of NF1 gene in the jaw lesion and treatment with curettage and bone substitute materials. J Craniomaxillofac Surg 44(8): 10541060, 2016. PMID: 27316856. DOI: 10.1016/j.jcms.2016.05.010

65 Tibbles JA and Cohen MM Jr: The Proteus syndrome: The Elephant Man diagnosed. Br Med J (Clin Res Ed) 293(6548): 683-685, 1986. PMID: 3092979. DOI: 10.1136/bmj.293.6548.683

66 National Institutes of Health Consensus Development Conference Statement: neurofibromatosis. Bethesda, Md., USA, July 13-15, 1987. Neurofibromatosis 1(3): 172-178, 1988. PMID: 3152465.

67 Messiaen LM, Callens T, Mortier G, Beysen D, Vandenbroucke I, Van Roy N, Speleman F and Paepe AD: Exhaustive mutation analysis of the NF1 gene allows identification of $95 \%$ of mutations and reveals a high frequency of unusual splicing defects. Hum Mutat 15(6): 541-555, 2000. PMID: 10862084. DOI: 10.1002/1098-1004(200006)15:6<541::AID-HUMU6>3.0.CO;2-N

68 Sapp JC, Hu L, Zhao J, Gruber A, Schwartz B, Ferrari D and Biesecker Md LG: Quantifying survival in patients with Proteus syndrome. Genet Med 19(12): 1376-1379, 2017. PMID: 28661492. DOI: $10.1038 /$ gim.2017.65

Received February 8, 2021

Revised February 25, 2021 Accepted March 8, 2021 